В. Д. Карлов ${ }^{1}$, О. Л. Кузнєцов ${ }^{1}$, А. М. Артеменко ${ }^{2}$ А. Д. Карлов ${ }^{1}$

${ }^{1}$ Харківський національний університет Повітряних Сил імені Івана Кожедуба, Харків, Україна

${ }^{2}$ Генеральний штаб Збройних Сил України, Київ, Україна

\title{
ТОЧНІСТЬ ОПТИМАЛЬНОГО ВИМІРЮВАННЯ РАДІАЛЬНОЇ ШВИДКОСТІ ЦІЛІ ПРИ ВРАХУВАННІ ФЛУКТУАЦЙ ПОЧАТКОВИХФАЗ РАДІОІМПУЛЬСІВ ПАЧКИ
}

\begin{abstract}
У статті розглядаються питання оцінювання радіальної швидкості при використанні когерентної пачки радіоімпульсів стосовно випадку наявності у відбитих від цілі радіоімпульсах корельованих флуктуацій початкових фаз. Оцінюється точність вимірювання частоти пачки для випадку оптимальної обробки з врахуванням фазових флуктуацій їі радіоімпульсів. Розгляд проводиться у припущенні, що на вхід приймального пристрою РЛС надходить адитивна суміш відбитих від цілей сигналів й некорельованого гаусівського шуму. Оптимальне оцінювання доплеровського зміщення частоти відбитого від цілі сигналу здійснюється за критерієм максимуму натурального логарифма відношення правдоподібності усередненого по усім можливим значенням випадкових неінформативних параметрів. Вважається, що фазові флуктуації радіоімпульсів прийнятої пачки розподілені за нормальним законом с нульовим середнім, а кореляція фазових флуктуацій зі збільшенням інтервалу між радіоімпульсами пачки убуває за експоненціальним або знакозмінним законами.

Ключов і слова: когерентно-імпульсна РЛС, пачка радіоімпульсів, фазові флуктуації, радіальна швидкість, гаусівський шум, відношення правдоподібності, оптимальне вимірювання, радіолокаційне спостереження, ефективність оптимізації.
\end{abstract}

\section{Вступ}

Постановка проблеми. Радіальна швидкість $\epsilon$ важливим параметром руху цілі, який дозволяє визначати динаміку і напрямок іï переміщення за результатом первинної обробки радіолокаційної інформації, а також обумовлюе можливість і якість подальшої вторинної обробки та супроводження цілі.

В когерентно-імпульсних РЛС, які в якості зондувального сигналу використовують когерентну пачку радіоімпульсів, ступінь когерентності якої пачки визначає міру роздільної здатності РЛС за радіальною швидкістю та точність вимірювання радіальної швидкості повітряного об'єкта.

Турбулентність атмосфери призводить до флуктуацій показника іiі заломлення та до випадкових змін фазової структури сигналу. У тропосфері, дане явище обумовлене флуктуаціями температури, вологості і тиску $[1,2]$. Рух реальної цілі приводить до зміни просторового положення складових іiі елементів і появі флуктуацій сумарного відбитого сигналу $[3,4]$. При радіопеленгу повітряних об'єктів на малих висотах виникають фазові флуктуації прийнятого сигналу відбитих від нерівномірних ділянок місцевості $[5,6]$.

Вказане свідчить про необхідність оптимізації часо-частотної обробки когерентної пачки шляхом врахування флуктуацій фаз їі радіоімпульсів. Оцінка точності вимірювання радіальної швидкості цілі за рахунок врахування фазових флуктуацій сигналу дозволить визначити умови доцільності вказаної оптимізації.

Аналіз останніх досліджень і публікацій. Радіолокаційному спостереженню цілей та вимірюванню їх координат й параметрів руху в складних умовах присвячена значна кількість робіт. Так, в роботах [7-10] розглядаються питання оптимального оцінювання радіальної швидкості цілі при іiї локації під малими кутами місця за наявністю спотворень фазової структури радіолокаційного сигналу.

Флуктуації фази, обумовлені наявністю атмосферних неоднорідностей та особливості застосування радіотехнічних систем в умовах їхнього впливу описані в роботах $[1,5,9,10]$. Окрім цього, складна форма цілі та здатність ії до виконання раптового маневру, обумовлює блукання іiі радіолокаційного центру та, як слід, появи фазових викривлень прийнятого сигналу та швидкісних шумів цілі $[1,3,4]$. Якщо радіолокаційне спостереження реалізується по цілям, що рухаються під малими кутами місця, та внаслідок багатотрасового поширення радіолокаційного сигналу з'являються його додаткові фазові викривлення, що розглядаються у $[3,5,6]$.

Результати наведені у даних роботах стосуються випаду використання в якості зондувального сигналу РЛС або монохроматичного випромінювання або поодиноких радіоімпульсів.

В сучасних когерентно-імпульсних РЛС для забезпечення радіолокаційного спостереження складних маневруючих цілей використовується когерентна пачка радіоімпульсів. Тому, має практичну користь оцінювання потенційних можливостей оптимізації часо-частотної обробки прийнятої пачки 3 врахуванням фазових флуктуацій ії радіоімпульсів.

Питання впливу корельованих фазових флуктуацій радіолокаційного сигналу на зниження якості його часо-частотної обробки та вимірювання радіальної швидкості цілі розглядалися в роботах [1114].

Результати оптимізації вимірювання частоти прийнятої пачки радіоімпульсів викладені в роботах [15-26].

Метою статті $є$ дослідження впливу статистичних характеристик флуктуацій початкових фаз радіоімпульсів прийнятої пачки на точність оптимального вимірювання радіальної швидкості цілі. 


\section{Основний матеріал}

Як показано в роботі [7], оцінювання радіальної швидкості цілі здійснюється згідно з виразом

$$
\mathrm{V}_{\mathrm{r}}=\frac{\lambda}{4 \pi} \Omega
$$

де $\Omega=2 \pi \mathrm{F}_{\text {д }}$ - циклічний доплерівський зсув часто-

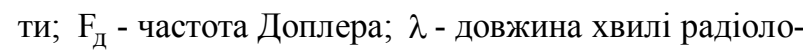
каційного сигналу.

Припускається, що прийнята реалізація представляє собою суму відбитої від цілі пачки радіоімпульсів та внутрішнього шуму приймального пристрою

$$
\mathrm{y}(\mathrm{t}, \Omega)=\mathrm{x}(\mathrm{t}, \Omega)+\mathrm{n}(\mathrm{t})
$$

де $\mathrm{y}(\mathrm{t}, \Omega)$ - реалізація прийнятого коливання; $\mathrm{x}(\mathrm{t}, \Omega)$ - реалізація корисного сигналу; $\mathrm{n}(\mathrm{t})$ - реалізація внутрішнього гаусівського шуму.

Корисним сигналом $є$ когерентна пачка радіоімпульсів 3 випадковою амплітудою і початковою фазою, комплексна амплітуда якої є такою

$$
\dot{\mathrm{X}}(\mathrm{t}, \Omega)=\mathrm{b} \sum_{\mathrm{i}=1}^{\mathrm{n}} \dot{\mathrm{X}}_{\mathrm{i}}(\mathrm{t}, \Omega) \exp [\mathrm{j}(\beta)]
$$

де $\dot{\mathrm{X}}_{\mathrm{i}}(\mathrm{t}, \Omega)$ - комплексна амплітуда i - го радіоімпульсу; b- випадкова амплітуда радіосигналу, яка розподілена за законом Релея; $\beta$ - випадкова початкова фаза радіосигналу, яка розподілена за рівномірним законом; і - номер радіоімпульсу, який відлічується від початку пачки; n - число радіоімпульсів в пачці.

В роботі [7] визначено, що відношення правдоподібності для когерентного сигналу з рівномірно розподіленою випадковою фазою й випадковою амплітудою, розподіленою за законом Релея, як результат статистичного усереднення за випадковими параметрами b i $\beta$ має вид

$$
\ell(\Omega)=\frac{1}{1+\frac{\mathrm{q}^{2}}{2}} \exp \frac{\frac{\mathrm{q}^{2}}{2}}{2\left(1+\frac{\mathrm{q}^{2}}{2}\right)}\left|\mathrm{Z}_{\mathrm{H}}(\Omega)\right|^{2},
$$

де $\mathrm{q}^{2}-$ відношення сигнал-шум за потужністю; $\left|Z_{\mathrm{H}}(\Omega)\right|^{2}$ - квадрат модулю нормованого комплексного вагового інтеграла як функція вимірюваного параметра.

В умовах регулярного вимірювання $\left(\mathrm{q}^{2}>>1\right)$ справедливою $є$ рівність

$$
\left|\mathrm{Z}_{\mathrm{H}}(\Omega)\right|=\left|\mathrm{Z}_{\mathrm{H}}\left(\vec{\Phi}_{\mathrm{c}}, \vec{\Phi}_{\mathrm{o}}\right)\right| \approx \mathrm{q} \rho\left(\vec{\Phi}_{\mathrm{c}} \vec{\Phi}_{\mathrm{o}}\right)=\mathrm{q} \rho(\Omega),
$$

де $\vec{\Phi}_{\mathrm{c}}=\left\|\Phi_{\mathrm{ci}}\right\|^{\mathrm{T}}(\mathrm{i}=1,2, \ldots, \mathrm{n})$ - вектор спостережуваних значень початкових фаз радіоімпульсів пачки; $\vec{\Phi}_{\mathrm{o}}=\left\|\Phi_{\mathrm{oi}}\right\|^{\mathrm{T}}$ - вектор очікуваних значень початкових фаз радіоімпульсів пачки; $\rho\left(\vec{\Phi}_{\mathrm{c}}, \vec{\Phi}_{\mathrm{o}}\right)=$ $=\rho(\Omega)-$ нормована функція розузгодження за початковою фазою спостережуваного та очікуваного радіосигналу.

3 урахуванням (5) відношення правдоподібності (5) при $\mathrm{q}^{2}>>1$ приймає вид

$$
\ell(\Omega) \approx \frac{2}{q^{2}} \exp \frac{q^{2} \rho^{2}(\Omega)}{2} .
$$

Отримаємо вираз дисперсії помилки вимірювання частоти пачки $\sigma_{\Omega}^{2}$ ппт. при оцінюванні оптимальним алгоритмом.

В даному випадку комплексна амплітуда корисного сигналу може бути записана наступним чином

$$
\dot{\mathrm{X}}(\mathrm{t}, \Omega)=\mathrm{b} \sum_{\mathrm{i}=1}^{\mathrm{n}} \dot{\mathrm{X}}_{\mathrm{i}}(\mathrm{t}, \Omega) \exp \left[\mathrm{j}\left(\beta+\varphi_{\mathrm{i}}\right)\right],
$$

де $\varphi_{i}$ - флуктуаційна складова початкової фази і-го радіоімпульсу.

В роботі [7] визначено, що оптимальне вимірювання доплеровського зсуву частоти пачки радіоімпульсів здійснюється шляхом знаходження аргументу максимуму натурального логарифму усередненого за всіма випадковими параметрами відношення правдоподібності

$$
\widehat{\Omega}_{\text {опт. }}=\arg \max \ln \bar{\ell}(\Omega),
$$

Усереднене відношення правдоподібності знаходилося згідно виразу

$$
\begin{gathered}
\bar{\ell}(\Omega)=\int_{\mathrm{b}} \int_{\beta \vec{\varphi}} \ell(\Omega / \mathrm{b}, \beta, \vec{\varphi}) \mathrm{p}(\mathrm{b}) \mathrm{p}(\beta) \mathrm{p}(\vec{\varphi}) \mathrm{db} \mathrm{d} \beta \mathrm{d} \vec{\varphi}= \\
=\int_{\vec{\varphi}} \ell(\Omega) \mathrm{p}(\vec{\varphi}) \mathrm{d} \vec{\varphi},
\end{gathered}
$$

де $\ell(\Omega / \mathrm{b}, \beta, \vec{\varphi})$ - умовне відношення правдоподібностей при фіксованих випадкових неінформативних параметрах очікуваного радіосигналу; $\vec{\varphi}=\left\|\varphi_{\mathrm{i}}\right\|$ вектор-стовпець значень флуктуаційних складових початкових фаз радіоімпульсів пачки; $\mathrm{p}(\mathrm{b}), \mathrm{p}(\beta)$ i $\mathrm{p}(\vec{\varphi})$ - щільності імовірності випадкової амплітуди, початкової фази пачкового радіосигналу і векторастовпця $\vec{\varphi}$ відповідно; $\ell(\Omega)$ - відношення правдоподібності (6), як результат статистичного усереднення за випадковими параметрами $\mathrm{b}$ i $\beta$; $\mathrm{d} \vec{\varphi}=\left(\mathrm{d} \varphi_{1} \mathrm{~d} \varphi_{2} \ldots \mathrm{d} \varphi_{\mathrm{n}}\right)^{\mathrm{T}}$.

Усереднене відношення правдоподібності (9) залежить від випадкових складових різниць фаз симетричних радіоімпульсів пачки і визначається як

$$
\bar{\ell}(\Omega)=\int_{(\Delta \vec{\varphi})} \ell(\Omega, \Delta \vec{\varphi}) \mathrm{p}(\Delta \vec{\varphi}) \mathrm{d} \Delta \vec{\varphi},
$$

де $\vec{\varphi}=\left\|\Delta \varphi_{\text {к }}\right\|$ - вектор-стовпець значень випадкових складових різниць фаз радіоімпульсів симетри- 
чних відносно центру пачки; $\mathrm{p}(\Delta \varphi)$ - закон розподілу щільності імовірності; $\mathrm{d} \Delta \vec{\varphi}=\mathrm{d} \Delta \varphi_{1} \mathrm{~d} \Delta \varphi_{2} \ldots \mathrm{d} \Delta \varphi_{\mathrm{m}}$.

Вираз розподілу щільності імовірності випадкових складових різниць фаз симетричних радіоімпульсів пачки отримано в [7] явному вигляді. 3 урахуванням нього усереднене відношення правдоподібності можна записати у вигляді:

$$
\begin{gathered}
\bar{\ell}(\Omega)=\mathrm{K} \int_{(\Delta \bar{\varphi})} \exp \left[-\frac{\mathrm{q}^{2}}{2}\left(\mathrm{a}_{1,1} \Delta \varphi_{1}^{2}+\mathrm{a}_{\mathrm{m}, \mathrm{m}} \Delta \varphi_{\mathrm{m}}^{2}+\right.\right. \\
+\sum_{\mathrm{k}=2}^{\mathrm{m}-1} \mathrm{a}_{\mathrm{k}, \mathrm{k}} \Delta \varphi_{\mathrm{k}}^{2}+2 \sum_{\mathrm{k}=1}^{\mathrm{m}-1} \mathrm{a}_{\mathrm{k}, \mathrm{k}+1} \Delta \varphi_{\mathrm{k}} \Delta \varphi_{\mathrm{k}+1}+ \\
\left.\left.+2 \sum_{\mathrm{k}=1}^{\mathrm{m}} \mathrm{a}_{\mathrm{k}, \mathrm{m}+1} \Delta \varphi_{\mathrm{k}}\right)\right] \mathrm{d} \Delta \varphi_{1} \mathrm{~d} \Delta \varphi_{2} \ldots \mathrm{d} \Delta \varphi_{\mathrm{m}}, \\
\times \mathrm{K}=\frac{2 \sqrt{1+\mathrm{a}}}{\mathrm{q}^{2}\left(2 \sqrt{2 \pi} \sigma_{\varphi}\right)^{\mathrm{m}}\left(1-\mathrm{a}^{2}\right)^{\mathrm{m} / 2} \times} \\
\left.\mathrm{a}_{\mathrm{m}, \mathrm{m}}=\frac{1}{2 \gamma(1+\mathrm{a})}+\frac{\mathrm{q}^{2}}{2}\left(1-\frac{1}{2} \sum_{\mathrm{k}=1}^{\mathrm{m}} \xi_{\mathrm{k}} \delta \Phi_{\mathrm{k}}^{2}\right)\right] ; \mathrm{a}_{1,1}=\frac{1+\mathrm{a}+\mathrm{a}^{2}}{2 \gamma(1+\mathrm{a})}+\frac{\xi_{1}}{2} \\
(\mathrm{k}=2,3, \ldots, \mathrm{m}-1) ; \mathrm{a}_{\mathrm{k}, \mathrm{k}+1}=\mathrm{a}_{\mathrm{k}+1, \mathrm{k}}=-\frac{1+\mathrm{a}^{2}}{2 \gamma(1+\mathrm{a})} \\
\mathrm{a}_{\mathrm{k}, \mathrm{m}+1}=\frac{\xi_{\mathrm{k}}}{2} \\
\delta \Phi_{\mathrm{m}+1, \mathrm{k}}=\frac{1}{2} \xi_{\mathrm{k}} \delta \Phi_{\mathrm{k}} ; \gamma=\mathrm{q}^{2} \sigma_{\varphi}^{2}(1-\mathrm{a})
\end{gathered}
$$

де

k - номер пари радіоімпульсів, симетричних відносно центру пачки; $\Delta \Phi_{\mathrm{k}}$ - різниці фаз симетричних відносно центру пачки радіоімпульсів k-ї пари.

Параметр $\gamma$ дозволяє одночасно враховувати вплив як внутрішніх шумів, так і корельованих фазових флуктуацій. Якщо вплив внутрішніх шумів переважає, то параметр $\gamma$ приймає малі значення $(\gamma<<1)$, а якщо переважає вплив фазових флуктуацій, то даний параметр досягає значних величин $(\gamma>>1)$.

Із співвідношення (11) видно, що в показнику експоненти, яка знаходиться під знаком інтеграла, містяться елементи, які утворюють квадратичну форму т змінних $\Delta \varphi$.

Для того, щоб взяти цей інтеграл, необхідно перейти від довільного запису квадратичної форми до їі канонічного. Тобто у співвідношенні (11) показник експоненти привести до:

$$
-\frac{\mathrm{q}^{2}}{2}\left(\sum_{\mathrm{k}=1}^{\mathrm{m}} \lambda_{\mathrm{k}} \mathrm{y}_{\mathrm{k}}^{2}+\frac{|\Delta|}{|\Theta|}\right)
$$

де $|\Theta|$ - визначник матриці $\Theta$ коефіцієнтів при членах другого ступеня квадратичної форми; $\overrightarrow{\mathrm{y}}=\left\|\mathrm{y}_{\mathrm{k}}\right\|-$ нові змінні; $\left\|\lambda_{\mathrm{k}}\right\|$ - власні значення матриці $\Theta$, отриманої викреслюванням $(\mathrm{m}+1)$-ої строки $\mathrm{i}(\mathrm{m}+1)$-го стовпця із матриці коефіцієнтів квадратичної форми $\Delta$, яка має такий визначник:

$$
|\Delta|=\left|\begin{array}{cccccc}
\mathrm{a}_{1,1} & \mathrm{a}_{1,2} & 0 & . & 0 & \mathrm{a}_{1, \mathrm{~m}+1} \\
\mathrm{a}_{2,1} & \mathrm{a}_{2,2} & \mathrm{a}_{2,3} & . & 0 & \mathrm{a}_{2, \mathrm{~m}+1} \\
0 & \mathrm{a}_{3,2} & \mathrm{a}_{3,3} & \cdot & 0 & \mathrm{a}_{3, \mathrm{~m}+1} \\
\cdot & \cdot & \cdot & \cdot & \cdot & \cdot \\
0 & 0 & \cdot & \mathrm{a}_{\mathrm{m}, \mathrm{m}-1} & \mathrm{a}_{\mathrm{m}, \mathrm{m}} & \mathrm{a}_{\mathrm{m}, \mathrm{m}+1} \\
\mathrm{a}_{\mathrm{m}+1,1} & \mathrm{a}_{\mathrm{m}+1,2} & \cdot & \mathrm{a}_{\mathrm{m}+1, \mathrm{~m}-1} & \mathrm{a}_{\mathrm{m}+1, \mathrm{~m}} & 0
\end{array}\right|
$$

Використовуючи вираз (12), усереднене відношення правдоподібності (11) представляється як:

$$
\begin{aligned}
& \bar{\ell}(\Omega) \cong K \exp \left(-\frac{\mathrm{q}^{2}}{2} \frac{|\Delta|}{|\Theta|}\right) \times \\
& \times \prod_{\mathrm{k}=1}^{\mathrm{m}} \int_{-\infty}^{\infty} \exp \left(-\frac{\mathrm{q}^{2} \lambda_{\mathrm{k}} \mathrm{y}_{\mathrm{k}}^{2}}{2}\right) \mathrm{dy}_{\mathrm{k}} .
\end{aligned}
$$

Враховуючи табличний інтеграл:

$$
\int_{-\infty}^{\infty} \exp \left(-\frac{\mathrm{q}^{2} \lambda \mathrm{y}^{2}}{2}\right) d y=\sqrt{\frac{2 \pi}{\mathrm{q}^{2} \lambda}}
$$

і властивість власних значень $\prod_{\mathrm{k}=1}^{\mathrm{m}} \lambda_{\mathrm{k}}$, отримаємо:

$$
\bar{\ell}(\Omega)=\mathrm{K} \prod_{\mathrm{k}=1}^{\mathrm{m}} \sqrt{\frac{2 \pi}{\mathrm{q}^{2} \lambda_{\mathrm{k}}}} \exp \left(-\frac{\mathrm{q}^{2}}{2} \frac{|\Delta|}{|\Theta|}\right) .
$$

Якщо взяти натуральний логарифм виразу (14) i залишивши залежні від вимірюваного параметра елементи, отримаємо співвідношення для достатньої статистики:

$$
\overline{\mathrm{S}}(\Omega)=\frac{\mathrm{q}^{2}}{2}\left(1-\frac{1}{2} \sum_{\mathrm{k}=1}^{\mathrm{m}} \xi_{\mathrm{k}} \delta \Phi_{\mathrm{k}}^{2}\right)-\frac{\mathrm{q}^{2}}{2} \frac{|\Delta|}{|\Theta|} .
$$

Елементи $(\mathrm{m}+1)$-ої строки і $(\mathrm{m}+1)$-го стовбця матриці $\Delta$ містять вимірюваний параметр. Використовуючи властивість визначника $|\Delta|$ його можна записати в наступному вигляді:

$$
|\Delta|=\sum_{\mathrm{k}=1}^{\mathrm{m}} \mathrm{a}_{\mathrm{k}, \mathrm{m}+1} \mathrm{~A}_{\mathrm{k}, \mathrm{m}+1},
$$

де $\mathrm{A}_{\mathrm{k}, \mathrm{m}+1}$ - алгебраїчне доповнення елемента $\mathrm{a}_{\mathrm{k}, \mathrm{m}+1}$ матриці $\Delta$.

Для виділення $\delta \Phi_{\mathrm{k}}$ властивість (16) застосовується повторно до елементів $(\mathrm{m}+1)$-ої строки матриці $\Delta$. Таким чином, формула для розрахунку визначника $|\Delta|$ приймає вигляд:

$$
|\Delta|=-\sum_{\mathrm{k}=1}^{\mathrm{m}}(-1)^{\mathrm{K}} \mathrm{a}_{\mathrm{k}, \mathrm{m}+1} \sum_{\mathrm{l}=1}^{\mathrm{m}} \mathrm{a}_{\mathrm{m}+1,1}(-1)^{1}\left|\Theta_{\mathrm{k}, 1}\right|=
$$




$$
-\frac{1}{4} \sum_{\mathrm{k}=1}^{\mathrm{m}}(-1)^{\mathrm{k}} \xi_{\mathrm{k}} \delta \Phi_{\mathrm{k}} \sum_{\mathrm{l}=1}^{\mathrm{m}}(-1)^{1} \xi_{1} \delta \Phi_{1}\left|\Theta_{\mathrm{k}, \mathrm{l}}\right|
$$

де $\left|\Theta_{\mathrm{k}, \mathrm{i}}\right|$ - мінор елемента k,i матриці $\Theta$.

3 урахуванням (17) і (15) отримаємо вираз для достатньої статистики:

$$
\begin{gathered}
\overline{\mathrm{S}}(\Omega)=\frac{\mathrm{q}^{2}}{2}\left\{1-\frac{1}{2}\left[\sum_{\mathrm{k}=1}^{\mathrm{m}} \xi_{\mathrm{k}} \delta \Phi_{\mathrm{k}}^{2}\left(1-\frac{1}{2|\Theta|} \xi_{\mathrm{k}}\left|\Theta_{\mathrm{k}, \mathrm{k}}\right|\right)-\right.\right. \\
\left.\left.-\frac{1}{|\Theta|} \sum_{\mathrm{k}=1}^{\mathrm{m}-1} \sum_{\mathrm{i}=\mathrm{k}+1}^{\mathrm{m}}(-1)^{\mathrm{k}+\mathrm{i}} \xi_{\mathrm{k}} \xi_{\mathrm{i}} \delta \Phi_{\mathrm{k}} \delta \Phi_{\mathrm{i}}\left|\Theta_{\mathrm{k}, \mathrm{i}}\right|\right]\right\} .
\end{gathered}
$$

Для дисперсіі $\sigma_{\Omega}^{2}$ помилки вимірювання частоти пачки згідно [16] справедливе співвідношення

$$
\frac{1}{\sigma_{\Omega}^{2}}=-\frac{\mathrm{d}^{2} \ln \bar{\ell}(\Omega)}{\mathrm{d} \Omega^{2}}=-\frac{\mathrm{d}^{2} \ln \overline{\mathrm{S}}(\Omega)}{\mathrm{d} \Omega^{2}} \text { при } \Omega=\widehat{\Omega},(19)
$$

де $\ln \bar{\ell}(\Omega)$ - натуральний логарифм усередненого відношення правдоподібності або його достатньої статистики $\overline{\mathrm{S}}(\Omega)$.

Вираз для дисперсії помилки оптимального вимірювання частоти пачки при врахуванні флуктуації фаз iï радіоімпульсів, 3 використанням співвідношень (18) і (19), має вид

$$
\begin{aligned}
& \frac{1}{\sigma_{\Omega \text { опт. }}^{2}}=\frac{\mathrm{T}^{2} \mathrm{q}^{2}}{2}\left\{\sum_{\mathrm{k}=1}^{\mathrm{m}} \xi_{\mathrm{k}}(2 \mathrm{k}-1)^{2}\left[1-\frac{1}{2|\Theta|} \xi_{\mathrm{k}}\left|\Theta_{\mathrm{k}, \mathrm{k}}\right|\right]-\right. \\
& \left.-\frac{1}{|\Theta|} \sum_{\mathrm{k}=1}^{\mathrm{m}-1} \sum_{1=\mathrm{k}+1}^{\mathrm{m}}(-1)^{\mathrm{k}+1} \xi_{1} \xi_{\mathrm{k}}(21-1)(2 \mathrm{k}-1)\left|\Theta_{\mathrm{k}, 1}\right|\right\} .(20)
\end{aligned}
$$

При переважному впливі аддитивного шуму $\gamma<<1$ вираз (20) приймає вид

$$
\frac{1}{\sigma_{\Omega \text { опт. }}^{2}}=\frac{\mathrm{q}^{2} \mathrm{~T}^{2}}{2} \sum_{\mathrm{k}=1}^{\mathrm{m}} \xi_{\mathrm{k}}(2 \mathrm{k}-1)^{2} .
$$

При переважному впливі корельованих фазових флуктуацій $(\gamma>>1)$, вираз (20) передворюється до виду (при $\mathrm{m} \geq 2$ )

$$
\begin{gathered}
\frac{1}{\sigma_{\Omega \text { опт. }}^{2}}=\frac{\mathrm{T}^{2}(1-\mathrm{a})(2 \mathrm{~m}-1)}{2 \sigma_{\varphi}^{2}(1+\mathrm{a})} \times \\
\times\left[\frac{\left(4(2 \mathrm{~m}-1)^{2}-1\right)(1-\mathrm{a})^{2}+(2 \mathrm{~m}-1-(2 \mathrm{~m}-3) \mathrm{a})}{(1-\mathrm{a})^{2}}\right] .
\end{gathered}
$$

На рис. 1 наданні графіки залежності добутку квадрата середньоквадратичної помилки оптимального вимірювання пачки 3 десяти радіоімпульсів і періоду їх слідування $\left(\sigma_{\Omega \text { опт. }} \mathrm{T}\right)^{2}$, отриманого згідно (22), від відношення сигнал-шум по потужності $\mathrm{q}^{2}$ (рис 1, а) та від дисперсії фазових флуктуацій (рис. 1, б) при експоненційному законі убування їх кореляції в межах пачки радіоімпульсів.

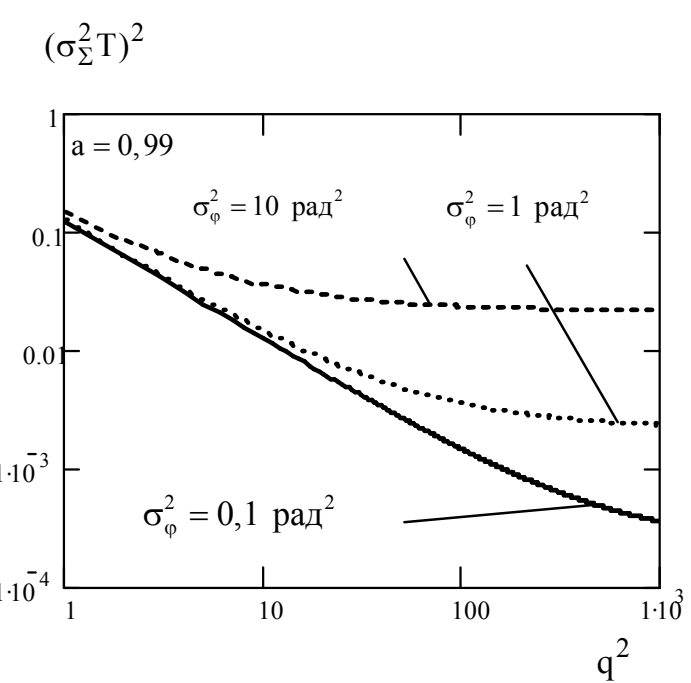

a

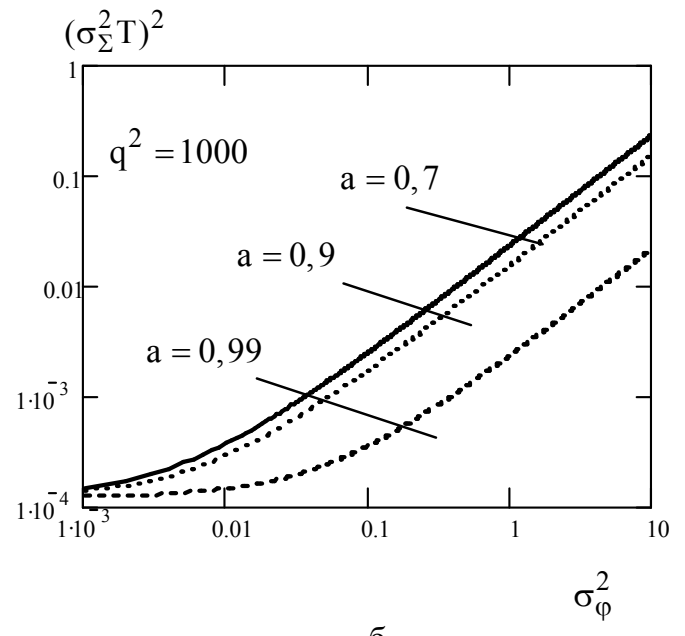

Рис. 1. Дисперсія помилки оптимального вимірювання частоти пачки радіоімпульсів при врахуванні фазових флуктуацій

Графіки на рис. 1, а відповідають значенню коефіцієнта міжімпульсної кореляції фазових флуктуацій $\mathrm{a}=0,99$ та різним величинам їх дисперсії

$$
\sigma_{\varphi}^{2}=0,1 ; 1 ; 10 \text { рад }^{2} .
$$

Графіки на рис. 1, б одержані для відношення сигнал-шум за потужністю $\mathrm{q}^{2}=1000$ та трьох випадків зниження коефіцієнта міжімпульсної кореляції фазових флуктуацій на $1 \%, 10 \%$ та $30 \%$ $(\mathrm{a}=0,99 ; 0,9 ; 0,7)$.

Результати наведені на рис. 1, а свідчать про те, що при малих значеннях відношення сигнал-шум точність оптимального вимірювання частоти пачки радіоімпульсів не залежить від статистичних характеристик фазових флуктуацій, а в умовах регулярного вимірювання (при $\mathrm{q}^{2}>>1$ ), навпаки, дані характеристики суттєво впивають на вказану точність.

Так, при зниженні коефіцієнта міжімпульсної кореляції фазових флуктуації лише на $1 \%$ ( $\mathrm{a}=0,99$ ), збільшення їх дисперсії на порядок в області суттєвих значень $\left(\sigma_{\varphi}^{2}=1 \ldots 10\right.$ рад $\left.^{2}\right)$, що $€$ 
характерним для реальних випадків, викликає до зростання дисперсії помилки вимірювання частоти пачки радіоімпульсів в декілька разів.

Наведені на рис. 1,б результати чисельного оцінювання свідчать про те, що при вимірюванні частоти пачки радіоімпульсів врахування фазових флуктуацій є доцільним, якщо їх дисперсія приймає значення $\sigma_{\varphi}^{2}=0,1 \ldots 10$ рад $^{2}$ і більше. При цьому, на величину дисперсії помилки вимірювання частоти пачки радіоімпульсів найбільш суттєвий вплив здійснює зменшення коефіцієнту міжімпульсної кореляції фазових флуктуацій в діапазоні $1 . . .0,9$ (зниження в межах 1..10\%), яке може спостерігатися в при виконанні РЛС завдань за призначенням у складній цільовій та завадовій обстановці.

При переважному впливі адитивного шуму $(\gamma<<1)$, на величину дисперсії помилки вимірювання частоти не впливають значення статистичних характеристик фазових флуктуацій. Вказані особливості враховує структура виразу (21) за допомогою якого оцінюється точність вимірювання частоти при $\gamma<<1$.

При переважному впливі корельованих фазових флуктуацій ( $\gamma>>1)$, основний внесок у точність вимірювання частоти вносять статистичні характе- ристики фазових флуктуацій - дисперсія і кореляція. Ці особливості враховує структура виразу (22) за допомогою якого оцінюється точність вимірювання частоти при $\gamma>>1$.

При проміжних значеннях параметра $\gamma$ на значення дисперсії помилки вимірювання частоти впливають як характеристики внутрішнього шуму приймального пристрою, так й значення статистичних характеристик фазових флуктуацій. В даному випадку оцінювання точності вимірювання частоти пачки радіоімпульсів доцільно проводити згідно виразу (20). Таким чином, отримані результати [27] дозволяють визначати значення параметра $\gamma$ при якому доцільно застосовувати співвідношення (20-22).

\section{Висновки}

При оптимальному оцінюванні, точність вимірювання радіальної швидкості цілі суттєво залежить від статистичних характеристик фазових флуктуацій - дисперсії і кореляції.

Ступінь впливу флуктуацій початкових фаз радіоімпульсів прийнятої пачки може бути визначена величиною параметра $\gamma=\mathrm{q}^{2} \sigma^{2}{ }_{\varphi}(1-\mathrm{a})$, що визначає особливості їх врахування при обробці радіосигналу в когерентно-імпульсних РЛС.

\section{СПИСОК ЛІТЕРАТУРИ}

1. Радиоэлектронные системы. Основы построения и теория / под. ред. Я.Д. Ширмана. - М: МАКВИС, 1998. - 828 с.

2. Вопросы статистической теории антенн /Я.С. Шифрін - М:Сов. радио, 1970. -383 с.

3. Справочник по радиолокации / Под ред. М. Сколника. - М: Сов. радио, 1976, Т 1. - 456 с.

4. Статистическая теория радиолокации протяженных целей / Р.В. Островитянов, Ф.А. Басалов - М: Радио и связь, 1982. - $232 \mathrm{c}$.

5. Влияние тропосферы и подстилающей поверхности на работу РЛС / Н.П. Красюк - М: Радио и связь, 1988. -223 с.

6. Котов А.Ф. Влияние отражений от подстилающей поверхности на процесс локации объектов // Теория и практика систем синхронизации / Московский институт радиотехники электроники и автоматики. - М.: - 1992. - C.4-8.

7. Постановка задачі оптимального оцінювання радіальної швидкості цілі при врахуванні корельованих флуктуацій початкових фаз радіоімпульсів прийнятої пачки / В.Д. Карлов, О.Л. Кузнєцов, А.М. Артеменко // Збірник наукових праць Харківського національного університету Повітряних Сил. - Х: ХНУПС, 2018. - Вип. 3 (57) - С. 115-121.

8. Оптимальне вимірювання координат та параметрів руху цілі у когерентно-імпульсній РЛС при врахуванні фазових спотворень радіолокаційного сигналу / О.Л. Кузнєцов, В.В. Бєлоусов, О.В. Лукашук, А.Д. Карлов // Збірник тез доповідей МНТК «Перспективи розвитку озброєння та військової техніки Сухопутних військ» - Львів, 2019. - С. 233.

9. К вопросу о измерении доплеровской частоты сигнала отраженного от цели лоцируемой за пределами радиогоризонта над морем / В.Д. Карлов, А.К. Кондратенко, А.К. Шейгас, Ю.Б. Ситник // Наука і техніка Повітряних Сил Збройних Сил України. - Х: ХУПС ім. І. Кожедуба, 2014. - Вип. 1 (14) - С. 115-117.

10. К вопросу об измерении радиальной составляющей скорости аэродинамической цели при ее локации над морем / В.Д. Карлов, Г.В. Певцов, И.А. Нос, М.М. Петрушенко // Тези доповідей 11 науково-технічної конференції «Створення та модернізація озброєння і військової техніки в сучасних умовах» - Ф: 8-9 вересня, 2011. - С. 108.

11. Петрушенко М.М. Особливості застосування радіотехнічних систем Повітряних Сил в нестабільних гідрометеорологічних умовах та стихійних метеорологічних явищах / М.М. Петрушенко // Системи управління навігації та зв'язку К: Центральний науково-дослідний інститут навігації і управління, 2009. - № 2 (10) - С. 54-57.

12. Ошибки измерения радиальной скорости и радиального ускорения цели, обусловленные неучетом флюктуаций фаз импульсов пачки / Н.Н. Минервин, А.Л. Кузнецов // АКТТ. - Х: ХАІ, 2001. - № 22 - С. 288-294.

13. Ограничение точности измерения радиальной скорости цели за счет условий распространения, отражения и обработки радиолокационного сигнала / М.М. Мінервін, О.Л. Кузнєцов, В.А. Таршин // Збірник наукових праць Харківського університету Повітряних Сил - Х: ХУПС, 2006. - № 3(9) - С. 116-118.

14. Коваленко А. А., Кучук Г. А. Методи синтезу інформаційної та технічної структур системи управління об'єктом критичного застосування. Сучасні інформаційні системи. 2018. Т. 2, № 1. С. 22-27. DOI: https://doi.org/10.20998/2522-9052.2018.1.04

15. Свиридов А. С., Коваленко А. А., Кучук Г. А. Метод перерозподілу пропускної здатності критичної ділянки мережі на основі удосконалення ON/OFF-моделі трафіку. Сучасні інформаційні системи. 2018. Т. 2, № 2. C. 139-144. DOI: https://doi.org/10.20998/2522-9052.2018.2.24

16. Evaluation of the accuracy of measuring the radial velocity of a target with an exponential and alternating decrease in phase correlation of the burst radio signal / V.D. Karlov O.L., Kuznietsov, A.M. Artemenko // Новітні технології - для захисту повітряного простору. - Х.: ТОВ «ДІСА ПЛЮС», 10 - 11 квітня, 2019. - С. 482. 
17. Помилка вимірювання радіальної швидкості цілі внаслідок впливу флуктуацій початкових фаз радіоімпульсів пачки / В.Д. Карлов, О.Л. Кузнєцов, А.М. Артеменко, А.Д. Карлов // Системи управління навігації та зв’язку. - Полтава : Полтавський національний технічний університет імені Юрія Кондратюка, 2019. - Вип. 1(53) - С. 61-65.

18. Кучук Г.А. Управління трафіком мультисервісної розподіленої телекомунікаційної мережі / Г.А. Кучук // Системи управління, навігації та зв'язку. - К.: ЦНДІ НіУ, 2007. - Вип. 2. - С. 18-27.

19. Кучук Г.А. Минимизация загрузки каналов святи вычислительной сети / Г.А. Кучук // Системи обробки інформації. - Х.: НАНУ, ПАНМ, ХВУ, 1998. - Вип. 1(5). - С. 149-154.

20. Кучук Г. А. Метод параметрического управления передачей данных для модификации транспортных протоколов беспроводных сетей / Г.А. Кучук, А.С. Мохаммад, А.А. Коваленко // Системи обробки інформації. - 2011. - № 8(98). - С. 211-218.

21. Кучук Г.А. Метод мінімізації середньої затримки пакетів у віртуальних з'єднаннях мережі підтримки хмарного сервісу / Г.А. Кучук, А.А. Коваленко, Н.В. Лукова-Чуйко // Системи управління, навігації та зв'язку. - Полтава . ПНТУ, 2017. - Вип. 2(42). - С. 117-120.

22. Kuchuk G., Kovalenko A., Komari I.E., Svyrydov A., Kharchenko V. Improving big data centers energy efficiency: Traffic based model and method. Studies in Systems, Decision and Control, vol 171. Kharchenko, V., Kondratenko, Y., Kacprzyk, J. (Eds.). Springer Nature Switzerland AG, 2019. Pp. 161-183. DOI: http://doi.org/10.1007/978-3-030-00253-4 _ 8

23. Кучук, Г.А. Синтез стратифікованої інформаційної структури інтеграційної компоненти гетерогенної складової Єдиної АСУ Збройними Силами України / Г.А. Кучук, О.П. Давікоза // Наука і техніка Повітряних Сил Збройних Сил України: науково-технічний журнал. - Х.: ХУ ПС, 2013. - № 3(12). - С. 154-158.

24. Оптимальный алгоритм измерения несущей частоты пачки радиоимпульсов с учетом флуктуаций их начальных фаз и аддитивных шумовых колебаний / Н.Н. Минервин, А.Л. Кузнецов // Радиотехника - Х: ХДТУРЕ, 2001. - № 122 С. $188-195$.

25. Оптимальные алгоритмы измерения радиальной скорости цели и угла прихода принимаемого радиосигнала с учетом фазовых флуктуаций, описываемых произвольной корреляционной функцией / Н.Н. Минервин, А.Л. Кузнецов, И.Е. Шумейко, В.А. Таршин // Радиотехника - Х: ХНУРЕ, 2006. - № 145 - С. 84-88.

26. Оптимізація вимірювання частоти та її похідних за часом когерентної пачки радіоімпульсів / Кузнєцов О.Л., Коломійцев О.В., Бєлоусов В.В., Черепньов І.А. // Інформаційні технології: наука, техніка, технологія, освіта, здоров'я: Mi-croCAD-2019 у 5 ч. Ч. V. за ред. проф. Сокола С.І. - Х: НТУ “ХПI”, 15-17 травня, 2019. -С. 95.

27. Точність оптимального вимірювання радіальної швидкості цілі при врахуванні флуктуацій початкових фаз радіоімпульсів пачки / В.Д. Карлов О.Л. Кузнєцов, А.М.Артеменко // Тези доповідей XV МНК ХНУПС ім. І. Кожедуба «Новітні технології - для захисту повітряного простору» 2019 року. - Х.: ТОВ «ДІСА ПЛЮС», 10 - 11 квітня, 2019. - С. 483.

Рецензент: д-р техн. наук, проф. Л. Ф. Купченко, Харківський національний університет Повітряних Сил імені Івана Кожедуба, Харків Received (Надійшла) 14.09.2019 Accepted for publication (Прийнята до друку) 23.10.2019

\section{Точность оптимального измерения радиальной скорости цели} при учете флуктуаций начальных фаз радиоимпульсов пачки

В. Д. Карлов, А. Л. Кузнецов, А. Н. Артеменко, А. Д. Карлов

В статье рассматриваются вопросы оценивания радиальной скорости при использовании когерентной пачки радиоимпульсов применительно к случаю наличия в отраженных от цели радиоимпульсах коррелированных флуктуацій начальних фаз. Оценивается точность измерения частоты пачки для случая оптимальной обработки с учетом фазових флуктуацій ее радиоимпульсов. Рассмотрение проводится в предположении, что на вход приемного устройства РЛС поступает аддитивная смесь отраженных от целей сигналов и некоррелированного гауссовского шума. Оптимальное оценивание доплеровского смещения частоты отраженного от цели сигнала осуществляется по критерию максимума натурального логарифма отношения правдоподобия усредненного по всем возможным значениям случайных неинформативных параметров. Предполагается, что фазовые флуктуации радиоимпульсов принятой пачки распределены по нормальному закону с нулевым средним, а корреляция фазовых флуктуаций с увеличением интервала между радиоимпульсами пачки убывает по экспоненциальному или знакопеременному законам.

Ключевые слов а: когерентно-импульсная РЛС, пачка радиоимпульсов, фазовые флуктуации, радиальная скорость, гауссовский шум, отношение правдоподобия, оптимальное измерение, радиолокационное наблюдение, эффективность оптимизации.

\section{Accuracy of optimal measurement of the target's radial velocity taking into account fluctuations of the radio pulse burst's initial phases}

V. Karlov, O. Kuznietsov, A. Artemenko, A. Karlov

The article deals with the estimation of the radial velocity when using a coherent burst of radio pulses as applied to the presence of correlated fluctuations of the initial phases in the radio pulses reflected from the target. The accuracy of the measurement of the burst frequency is evaluated for case of optimal processing with taking into account the phase fluctuations of its radio pulses. The signals at the input of the radar's receiver is an additive mixture of signals reflected from the targets, and uncorrelated Gaussian noise, that is the assumption of investigating. The Doppler shifts of the signals' frequency reflected from the targets are carried out by the criterion of the natural logarithm maximum for likelihood ratio of the random non-informative parameters averaged over all possible values have been estimated. It is assumed, that the phase fluctuations of the received radio pulses bursts are distributed according to normal probability laws with zero mean, and correlations of phase fluctuations decrease with exponential or alternating, sign-variable laws by increasing interval between radio pulses within the bursts.

Keywords : coherent pulse radar, burst of radio pulses, phase fluctuations, radial velocity, Gaussian noise, likelihood ratio, optimal measurement, radar surveillance, optimization efficiency. 